\title{
RENDIMENTO E CONSERVABILIDADE PÓS-COLHEITA DE GENÓTIPOS DE CEBOLA CULTIVADOS EM SOLO DE VÁRZEA
}

\author{
YIELD AND POSTHARVEST STORABILITY OF \\ ONION GENOTYPES GROWN IN LOWLAND
}

\author{
Jorge Nadir Trevisan ${ }^{1}$ Gustavo Adolfo Klippel Martins ${ }^{2}$ \\ Sidinei José Lopes ${ }^{3}$ Danton Camacho Garcia ${ }^{3}$
}

RESUMO

Para determinar o rendimento de bulbos curados de seis genótipos de cebola cultivados em solo de várzea, e a conservabilidade pós-colheita destes, em ambiente natural, foram conduzidos dois experimentos na Universidade Federal de Santa Maria, em 1995 e 1996. Todos os genótipos apresentaram rendimento comercial acima de 20t/ha. Os genótipos 'Crioula' apresentaram os melhores rendimentos quanti-qualitativos. Houve diferenca significativa para rendimento comercial e não comercial, peso médio de bulbos e rendimento de bulbos classes 2 e 3 . Até 100 dias de armazenamento, os bulbos de todos os genótipos sofreram perda de peso de cerca de $15 \%$. Não houve interação significativa entre genótipos e número de dias de armazenamento. Houve correlação entre perdas de peso e número de bulbos e duração do período de armazenamento. Houve correlação negativa entre o número e o peso dos bulbos e as percentagens de perda de peso e de número de bulbos.

Palavras-chave: cebola, genótipos, rendimento, conservabilidade.

\section{SUMMARY}

To determine yield of six onion genotypes grown in lowland, and postharvest room storability of cured bulbs, two experiments were performed at the Federal University of Santa Maria in 1995 and 1996. Yields of marketable bulbs were over 20t/ha for all genotypes under study. Yields of 'Crioula' genotypes were the highest, quantitatively and qualitatively. Marketable bulb yields, culls, average bulb weight and yields of bulb grades 2 and 3 were significantly different. Up to 100 days under storage, bulb weight loss was approximately $15 \%$ for all genotypes. No significant interaction between genotypes and storage period was found. Losses in bulb weight and bulb number correlated with storage period. Bulb number and bulb weight correlated negatively with percentages of bulb weight loss and bulb number loss.

Key words: onion, genotypes, yield, postharvest storability.

\section{INTRODUÇÃO}

Na década de 80, a produção nacional anual de cebola variou de 639 a 854 mil toneladas (EMPASC, 1991), sucedendo-se as safras de agosto a janeiro (COSTA, 1995). As diferentes regiões produtoras do País abastecem o mercado interno durante todo o ano, ocorrendo excesso de oferta de novembro a maio e escassez de oferta de junho a outubro. A área cultivada e a produção de cebola no Rio Grande do Sul, que eram as maiores do Brasil até 1977 , decresceram até 1990 , tendo-se mantido a baixa produtividade histórica de cerca de 8,0t/ha (FIBGE, 1980/1993). Em outros Estados, ocorreram aumentos de área plantada e de produção (EMPASC, 1991).

Embora alguns cultivares novos já estejam sendo usados comercialmente, como Aurora, Primavera, Madrugada, Petrolini e Crioula Alto Vale, muita cebola colhida no Rio Grande do Sul ainda provém de populações que recebem denominações diversas baseadas na forma e cor dos bulbos e duração do ciclo (IPAGRO, 1988). Segundo BENDJOUYA (1980), essas populações são origi-

\footnotetext{
${ }^{1}$ Engenheiro Agrônomo, Especialista, Professor Adjunto, Departamento de Fitotecnia, Centro de Ciências Rurais (CCR) Universidade Federal de Santa Maria (UFSM), 97105-900. Santa Maria, RS. Autor para correspondência.

${ }^{2}$ Engenheiro Agrônomo, Mestre, Professor Titular, Departamento de Fitotecnia, CCR, UFSM.

${ }^{3}$ Engenheiro Agrônomo, Mestre, Professor Assistente, Departamento de Fitotecnia, CCR, UFSM.
} 
nadas da cebola introduzida no Estado pelos imigrantes açorianos, constituindo material genético heterogêneo de baixa produtividade decorrente da alogamia, variabilidade genética da qual foram selecionados os tipos, de valor comercial, Baia Periforme, Amarela Globular e Pera.

A ausência de casca ou casca fina e bulbos esverdeados desuniformes são apontados por COSTA (1995) como problemas da cebola Baia Periforme, também identificada como cultivar (MASCARENHAS, 1980; EMBRAPA, 1991; EMPASC, 1991; GANDIN et al., 1997). A variabilidade da forma dos bulbos e grave contaminação genética, que resulta em percentuais expressivos de bulbos roxos, são defeitos importantes da cebola denominada Crioula (GANDIN et al., 1997), anteriormente identificada como EMPASC 357-Seleção Crioula (EMPASC, 1984), que podem, segundo COSTA (1995), ser corrigidos através de melhoramento.

O cultivar Valenciana, de casca múltipla, bulbos globulares e sabor adocicado, importado da Argentina, com excelente aceitação pelo mercado consumidor nacional, não bulbifica nas condições climáticas do Brasil (COSTA, 1995). O fotoperíodo é limitante para introdução de cultivares de cebola (BENDJOUYA, 1980). Onde a exigência fotoperiódica varietal não é satisfeita não há bulbificação ou há formação de bulbos pequenos e charutos (MASCARENHAS, 1980).

No Rio Grande do Sul, em nível de produtor, a estocagem da cebola curada é precária e feita em galpões rústicos, nos quais é colocada em varais, com circulação de ar natural, ou empilhada, sendo a umidade relativa alta um fator que acelera a brotação dos bulbos (FEE, 1978). A temperatura também influencia a brotação da cebola armazenada. Temperaturas ao redor de $30^{\circ} \mathrm{C}$, segundo SATURNINO \& MEDINA (1980), conservam os bulbos de cebola sem brotação durante até um ano, podendo, entretanto, nessas condições, ocorrer alta perda de peso, sobretudo por dessecação ou desidratação.

Perda d'água, brotação, enraizamento e podridões são os processos que dificultam a conservação da cebola após a colheita, determinando a deterioração dos bulbos (SANTOS \& ARAÚJO, 1993), havendo variação de conservabilidade entre cultivares (MASCARENHAS et al., 1978; BENDJOUYA, 1983; SANTOS \& ARAÚJO, 1993). As condições climáticas e edáficas, práticas culturais e manejo do produto a partir da colheita também afetam a conservação dos bulbos de cebola (WERNER, 1988; SANTOS \& ARAÚJO, 1993). RYALL \& LIPTON (1972) consideram o cultivar o fator mais importante na conservação pós-colheita da cebola.

MASCARENHAS et al. (1978), citados por SATURNINO \& MEDINA (1980), verificaram que a perda de peso em bulbos de cebola armazenados em condições naturais era contínua durante o período de armazenamento, variando, com os cultivares de 1 a $18 \%$ do peso inicial aos 30 dias após a colheita. Há influência do tamanho dos bulbos na perda de peso, sendo mais rápida nos bulbos maiores, SATURNINO \& MEDINA (1980). Perdas de peso de $14,5 \%$, aos 87 dias de armazenamento, foram observadas por HOYLE, citado por WERNER (1988), em bulbos de cebola curados a campo.

Para a conservação da cebola após a colheita, segundo RYALL \& LIPTON (1972), a umidade relativa ambiente deve ser mantida abaixo do nível favorável ao crescimento de raízes. Este nível varia geralmente de 65 a $75 \%$, ocorrendo desidratação forte dos bulbos, secamento e desprendimento das películas externas em condições de umidade relativa abaixo de $50 \%$.

A cebola produzida no Rio Grande do Sul tem boa qualidade e resiste a períodos de armazenamento razoavelmente longos (BENDJOUYA, 1980; GARCIA \& PORTO, 1990).

Os objetivos deste trabalho foram avaliar a produtividade de seis genótipos de cebola cultivados em solo de várzea e a conservabilidade póscolheita dos bulbos curados armazenados em condições naturais.

\section{MATERIAL E MÉTODOS}

O experimento foi conduzido no campus da Universidade Federal de Santa Maria, RS, no ano agrícola de 1995/96, em solo pertencente à unidade de mapeamento Vacacaí e classificado como Planossolo (BRASIL, 1973).

O delineamento experimental utilizado foi o de blocos ao acaso com seis tratamentos e quatro repetições. Os tratamentos constaram dos genótipos 'Crioula Lote 132', 'Crioula Lote 231', 'Crioula Lote 245' (Granja Wilson), 'Baia Periforme' (Isla), 'Norte 14' (Feltrin) e 'Baia Periforme' (Topseed). As parcelas, dispostas em canteiros, tinham área total de $2,40 \mathrm{~m}^{2}$, com quatro fileiras de plantas no espaçamento de $0,25 \times 0,12 \mathrm{~m}$, perfazendo um total de 80 plantas.

O leito da sementeira , composto por uma mistura de cama de curral, solo fértil e areia na proporção $1: 2: 1$, recebeu adubação de cultivo com $100 \mathrm{~g} / \mathrm{m}^{2}$ de superfosfato simples e $30 \mathrm{~g} / \mathrm{m}^{2}$ de cloreto de potássio.

A semeadura foi executada em 31/03. Na sementeira foram feitas até duas irrigações diárias 
por aspersão, escarificações, mondas e uma adubação de cobertura com $10 \mathrm{~g} / \mathrm{m}^{2}$ de sulfato de amônio aos 30 dias após a emergência.

A adubação em pré-transplante baseou-se nas Recomendações de Adubação e de Calagem para os Estados do Rio Grande do Sul e Santa Catarina (COMISSÃO DE FERTILIDADE DO SOLORS/SC, 1995) e pela Empresa Catarinense de Pesquisa Agropecuária S.A. (EMPASC., 1991) e constou de $200 \mathrm{~kg} / \mathrm{ha}$ de fósforo, $90 \mathrm{~kg} / \mathrm{ha}$ de potássio e $40 \mathrm{~kg} / \mathrm{ha}$ de nitrogênio.

O transplante foi feito 90 dias após a semeadura, quando as mudas atingiram 4 a 6 folhas verdadeiras, diâmetro da haste entre 3 e $6 \mathrm{~mm}$ e altura de $0,25 \mathrm{~m}$. As operações de manejo necessárias à condução do experimento foram a irrigação, o controle de ervas daninhas e adubações de cobertura. Em períodos de deficiência hídrica, manteve-se a umidade do solo através de até duas irrigações semanais por aspersão. As plantas daninhas foram controladas com duas capinas. As adubações de cobertura foram feitas com $30 \mathrm{~kg} / \mathrm{ha}$ de nitrogênio aos 30 e 45 dias após o transplante

A colheita, para todos os tratamentos, foi realizada em 17/11, 229 dias após a semeadura, quando 40 a $50 \%$ das plantas já tinham sofrido estalo (EMPASC, 1991). Utilizou-se uma área útil de $1,92 \mathrm{~m}^{2}$ da qual arrancaram-se manualmente 64 plantas. A cura foi feita a campo, durante dois dias, e concluída em galpão, no qual as plantas foram arranjadas sobre piso de alvenaria.

Após o período de cura de 42 dias, foi feita a limpeza dos 64 bulbos colhidos por parcela, cortando-se hastes e raízes e retirando-se as películas soltas e/ou sujas. Os bulbos foram classificados de acordo com as normas da Portaria Ministerial N ${ }^{\circ} 99$ (MINISTÉRIO DA AGRICULTURA, 1982) em: graúdos (diâmetro horizontal maior de $80 \mathrm{~mm}$ ), médios (diâmetro horizontal de 60 a menos de $80 \mathrm{~mm}$ ), pequenos (diâmetro horizontal de 40 a menos de $60 \mathrm{~mm}$ ) e miúdos (diâmetro horizontal de 20 a menos de 40mm). Separaram-se também os bulbos não comerciais (florescidos e deteriorados). Contaram-se os bulbos e efetuaram-se pesagens por classe.

Cinquienta dias após a colheita, selecionaram-se 40 bulbos uniformes e sadios por parcela e fez-se a primeira pesagem, iniciando-se a avaliação da capacidade de conservação em ambiente natural. Os bulbos pesados foram acondicionados em sacos de polipropileno telado, usados para a comercialização da cebola, e pendurados dentro de um galpão com telhado de fibroamianto, piso de alvenaria e paredes de madeira. Nas avaliações seguintes, aos 100, 150, 200 e 250 dias após a colheita, foram sendo eliminados os bulbos deteriorados e pesados os comercializáveis remanescentes. Para as avaliações no período de armazenamento, estudaram-se os genótipos e os dias após a colheita através de um esquema bifatorial. Utilizou-se a análise de regressão para procurar uma equação que ajustasse a perda de peso e o número dos bulbos durante o período de armazenamento. Para comparação dos genótipos, realizou-se o teste de Duncan (5\%).

\section{RESULTADOS E DISCUSSÃO}

Os rendimentos totais médios comerciais e não comerciais e o peso médio de bulbos dos genótipos avaliados são apresentados na tabela 1. As classes 1 e 4 de bulbos foram excluídas da análise de variância devido à freqüência muito baixa.

O genótipo 'Crioula 132' apresentou o maior rendimento comercial e peso médio de bulbo, o qual não diferiu estatisticamente dos genótipos 'Crioula 231' e 'Crioula 245'. O menor rendimento comercial e o menor peso médio de bulbo foi do genótipo 'Baia Periforme' (Topseed), não tendo, no entanto, diferido dos genótipos 'Pera Norte 14' (Feltrin) e 'Baia Periforme (Isla).

O melhor genótipo em relação ao rendimento não comercial foi o 'Crioula 132', não diferindo significativamente dos genótipos 'Baia Periforme' (Isla e Topseed). O maior rendimento não

Tabela 1 - Rendimentos médios totais ( $\mathrm{kg} / \mathrm{ha}$ ) de bulbos curados e peso médio de bulbos (g), de seis genótipos de cebola, aos 50 dias após a colheita.

\begin{tabular}{lccc}
\hline & Rendimentos médios totais & $\begin{array}{c}\text { Peso médio } \\
\text { de } \\
\text { Genótipos }\end{array}$ & bulbos \\
\cline { 2 - 3 } & Comercial & Não comercial & \\
& & & \\
\hline & & & $143 \mathrm{a}$ \\
Crioula Lote 132 (Granja Wilson) & $24.982 \mathrm{a} *$ & $605 \mathrm{c}$ & $141 \mathrm{a}$ \\
Crioula Lote 231 (Granja Wilson) & $22.888 \mathrm{ab}$ & $2.378 \mathrm{a}$ & $136 \mathrm{ab}$ \\
Crioula Lote 245 (Granja Wilson) & $22.834 \mathrm{ab}$ & $1.774 \mathrm{~b}$ & $130 \mathrm{bc}$ \\
Baia Periforme (Isla) & $21.788 \mathrm{bc}$ & $807 \mathrm{c}$ & $128 \mathrm{bc}$ \\
Pera Norte 14 (Feltrin) & $21.615 \mathrm{bc}$ & $1.509 \mathrm{~b}$ \\
Baia Periforme (Topseed) & $20.167 \mathrm{c}$ & $977 \mathrm{c}$ & $125 \mathrm{c}$ \\
& & & \\
\hline & & & \\
CV (\%) & 6,61 & 18,83 & \\
& & & \\
\hline
\end{tabular}

*Tratamentos com médias seguidas por letras distintas, na vertical, diferem entre si pelo teste de Duncan em nível de 5\% de probabilidade. 
comercial foi do genótipo 'Crioula 231', que diferiu significativamente dos demais.

Em relação ao rendimento comercial, o genótipo 'Crioula 231', que não diferiu dos genótipos 'Baia Periforme' (Isla) e 'Pera Norte 14' (Feltrin), deles diferiu relativamente ao peso médio de bulbos.

Os rendimentos médios de bulbos das classes comerciais 2 e 3 encontram-se na tabela 2 . Os genótipos com maior rendimento comercial total tiveram também os maiores rendimentos dentro da classe 2 de bulbos. $\mathrm{O}$ grupo de maior rendimento da classe 2 foi constituído dos genótipos 'Crioula', salientando-se 'Crioula 132', que apresentou diferença significativa em relação aos outros dois genótipos do grupo. O genótipo 'Baia Periforme' (Topseed) teve o menor rendimento comercial total e o menor rendimento na classe 2 , diferindo dos demais. Dentro da classe 3, o genótipo 'Baia Periforme' (Isla) teve o maior rendimento, diferindo dos demais. O menor rendimento comercial dentro da classe 3 foi o do genótipo 'Crioula 231'.

Após um período de armazenamento de 100 dias, a perda de peso dos bulbos dos genótipos estudados foi de aproximadamente $15 \%$, verificação concordante com a de HOYLE, citado por WERNER (1988), mas menor que a encontrada por MASCARENHAS et al. (1978), citados por SATURNINO \& MEDINA (1980).

Na tabela 3, são apresentadas as médias do percentual de perda de peso total e do número total de bulbos de cebola durante os 250 dias de

Tabela 2 - Rendimentos médios (kg/ha) das classes comerciais 2 e 3 de bulbos curados, de seis genótipos de cebola aos 50 dias após a colheita.

\begin{tabular}{|c|c|c|}
\hline \multirow{2}{*}{ Genótipos } & \multicolumn{2}{|c|}{ Rendimentos médios } \\
\hline & Classe 2 & Classe 3 \\
\hline Crioula Lote 132 (Granja Wilson) & $14.172 \mathrm{a}^{*}$ & $10.810 \mathrm{bc}$ \\
\hline Crioula Lote 231 (Granja Wilson) & $13.196 \mathrm{~b}$ & $9.692 \mathrm{~d}$ \\
\hline Crioula Lote 245 (Granja Wilson) & $12.481 \mathrm{~b}$ & $10.353 \mathrm{c}$ \\
\hline Baia Periforme (Isla) & $10.280 \mathrm{c}$ & $11.508 \mathrm{a}$ \\
\hline Pera Norte 14 (Feltrin) & $10.712 \mathrm{c}$ & $10.903 \mathrm{~b}$ \\
\hline Baia Periforme (Topseed) & $9.405 \mathrm{~d}$ & $10.762 \mathrm{bc}$ \\
\hline $\mathrm{CV}(\%)$ & 4,36 & 3,10 \\
\hline
\end{tabular}

*Tratamentos com médias seguidas por letras distintas, na vertical, diferem entre si pelo teste de Duncan em nível de 5\% de probabilidade.
Tabela 3 - Médias do percentual de perda de peso total (\% PPTB) e do número total (\% PNTB) de bulbos de cebola durante os 250 dias de conservação (armazenamento $=200$ dias) para seis genótipos de cebola.

\begin{tabular}{lcc}
\hline \multicolumn{1}{c}{ Genótipos } & \% PPTB & $\%$ PNTB \\
& & \\
\hline & & \\
Crioula Lote 132 (Granja Wilson) & $29,06 \mathrm{bc} *$ & $22,25 \mathrm{bc}$ \\
Crioula Lote 231 (Granja Wilson) & $26,70 \mathrm{c}$ & $18,38 \mathrm{c}$ \\
Crioula Lote 245 (Granja Wilson) & $35,05 \mathrm{a}$ & $26,25 \mathrm{a}$ \\
Baia Periforme (Isla) & $29,41 \mathrm{bc}$ & $21,63 \mathrm{bc}$ \\
Pera Norte 14 (Feltrin) & $28,96 \mathrm{bc}$ & $19,38 \mathrm{c}$ \\
Baia Periforme (Topseed) & $33,10 \mathrm{ab}$ & $26,88 \mathrm{ab}$ \\
& & \\
\hline
\end{tabular}

*Tratamentos com médias seguidas por letras distintas, na vertical, diferem entre si pelo teste de Duncan em nível de 5\% de probabilidade.

armazenamento. A contínua perda de peso dos bulbos armazenados durante 250 dias está de acordo com o que afirmam MASCARENHAS et al. (1978). A conservabilidade observada corrobora as afirmações de BENDJOUYA (1980) e GARCIA \& PORTO (1990). Não houve interação significativa entre os genótipos e o número de dias de armazenamento após a colheita

O genótipo "Crioula 245' apresentou o maior percentual de perda de peso e de número de bulbos, não diferindo significativamente do 'Baia Periforme' (Topseed). O genótipo 'Crioula 231' foi o que teve menor percentual de perda de peso e de número de bulbos, diferindo dos genótipos 'Crioula 245' e 'Baia Periforme' (Topseed), evidenciando variação de conservabilidade reportada por MASCARENHAS $\boldsymbol{e}$ t al. , 1978; BENDJOUYA, 1983 e SANTOS \& ARAÚJO, 1993.

Na figura 1, são apresentadas as equações para as regressões lineares entre os números de dias de armazenamento de bulbos após a colheita e as perdas percentuais de peso e de número de bulbos.

Analisando a correlação entre algumas variáveis em estudo, pelo coeficiente de correlação de Pearson, observou-se uma correlação de 0,94 $(\propto=5 \%)$ entre as variáveis peso e número de bulbos para todos os genótipos. O genótipo 'Baia Periforme' (Topseed) foi o único que não apresentou correlação entre o peso médio de bulbos e as percentagens de perda de peso e de perda de número de bulbos; para os demais genótipos houve correlação de $0,73(\propto=5 \%)$. Houve correlação $-0,98(\propto=5 \%)$ entre número de bulbos e percentagens de perda de peso e de número de bulbos para todos os genótipos, repetindo-se a mesma correlação entre peso de bul- 


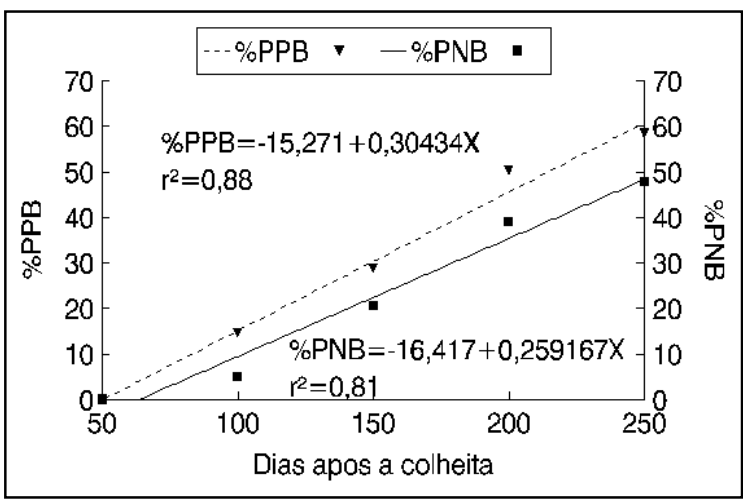

Figura 1 - Relação entre o número de dias após a colheita e os percentuais de perdas de peso (\%PPB) e do número de bulbos (\%PNB) de cebola. Santa Maria, RS.1995/96.

bos e percentagens de perda de peso e de número de bulbos.

\section{CONCLUSÃO}

Em solo de várzea, sob condições satisfatórias de cultivo, pode obter-se rendimento superior a $20 t /$ ha de bulbos comerciais de cebola. Os genótipos 'Crioula' apresentam melhor rendimento quanti-qualitativo. Os bulbos dos seis genótipos, desde que adequadamente curados e armazenados, suportam período de armazenamento natural de até 100 dias, com perdas de peso próximas a $15 \%$. É possível o armazenamento de bulbos curados até 250 dias, sendo as perdas correlacionadas com a duração do período de armazenamento.

\section{REFERÊNCIAS BIBLIOGRÁFICAS}

BENDJOUYA, B. Aspectos gerais da cultura da cebola no Rio Grande do Sul. IPAGRO INFORMA, Porto Alegre, n. 22, p. $7-13,1980$.

BRASIL. Fundação Instituto Brasileiro de Geografia e Estatística. Anuários Estatísticos do Brasil. Brasília: IBGE, 1980/93.

BRASIL. Ministério da Agricultura. Secretaria Nacional de Abastecimento-CTNP. Normas de identidade, qualidade e embalagem para classificação e comercialização da cebola, Brasília, v. 4, n. 3, 1982.

BRASIL. Ministério das Agricultura. Departamento Nacional de Pesquisa Agropecuária. Divisão de Pesquisa Pedológica.
Levantamento de reconhecimendo de solos do Estado do Rio Grande do Sul. Recife, 1973. 431 p. Boletim Técnico, 30 .

COMISSÃO DE FERTILIDADE DO SOLO-RS/SC. Recomendações de adubação e de calagem para os estados do Rio Grande do Sul e de Santa Catarina. 3. ed. Passo Fundo: CNPT/EMBRAPA, 1994. 224 p.

COSTA, C.P. da. Cebola cascuda: um desafio para a cebolicultura brasileira. SOB Informa, Curitiba, v. 14, n. 1 e 2, p. 13-14, 1995.

EMBRAPA-CNPFT, EMATER-RS. Cultura da cebola. Pelotas: EMBRAPA, 1991. 5 p. Sistema simplificado de produção, 5.

EMPASC. Nova cultivar de cebola: EMPASC 351 -Seleção Crioula. Florianópolis: EMPASC, 1984. 2 p. Documentos, 29.

EMPASC, EMATER-SC/ACARESC. Sistemas de produção para cebola. Florianópolis: EMPASC, 1991. 51 p. Sistemas de Produção, 16.

GANDIN, C.L., THOMAZELLI, L.F., ZIMMERMANN FILHO, A.A. Cebola. In: Recomendações de cultivares para o Estado de Santa Catarina 1997/1998. Florianópolis: EPAGRI, 1997. p. 44-45. Boletim Técnico, 82.

GARCIA, A., PORTO, V.H. da F. Cebola precoce: uma atividade rentável para os olericultores gaúchos. HortiSul, Pelotas, v. 1, n. $2,1989$.

IPAGRO. Estação Experimental de Rio Grande. Cebola. Relatório de atividades. 1988. (Mimeografado).

MASCARENHAS, M.M.T. Cultivares de cebola. Informe Agropecuário, Belo Horizonte, v. 6, n. 62, p. 17-20, 1980.

RIO GRANDE DO SUL. Secretaria de Coordenação e Planejamento. Fundação de Economia e Estatística. Programa comercialização Rio Grande do Sul - Produtos selecionados da lavoura. Porto Alegre: FEE, 1990. 85 p.

RYALL, A.L., LIPTON, W.J. Handling, transportation and storage of fruits and vegetables. Westport: The Avi, 1972. Cap. 9: Commodity requirements of underground structures: p. 167-189.

SANTOS, R. de F.A., ARAÜJO, M.de T. Conservação póscolheita da cebola 'São Paulo'. Horticultura Brasileira, Brasília, v. 11, n. 1, p. 41-42, 1993.

SATURNINO, H..M., MEDINA, P.V.L. Armazenamento da cebola. Informe Agropecuário, Belo Horizonte, v. 6, n. 62, p. $65-70,1980$.

WERNER, R.A. Colheita, cura e armazenamento. In: SEMINÁRIO NACIONAL DA CEBOLA, 3, 1988. Jaboticabal, SP. Anais... Jaboticabal: UNESP, 1988. 140 p., p. 63-91.

Ciência Rural, v. 29, n. 3, 1999. 